\title{
ANÁLISE DO CUESTIONARIO DO BARÓMETRO DO CIS DE ABRIL DE 2020
}

\author{
CARPENTE SARdĩ̃a, José ANTONio \\ Profesor de Matemáticas no IES de Fene (1989-2019) \\ jcarpente@edu.xunta.es
}

\section{Resumo}

Neste artigo preténdese poñer énfase na importancia da elaboración do cuestionario dunha enquisa para minimizar os erros e facela, xa que logo, de máis calidade e utilidade.

Primeiramente, repásanse os distintos tipos de erros que poden aparecer ao elaborar unha enquisa; a continuación, enuméranse distintas técnicas e estratexias para minimizar eses erros; finalmente, faise unha análise dalgunhas preguntas do barómetro do CIS de abril de 2020.

\section{Abstract}

This article aims to emphasize the importance of the elaboration of a survey questionnaire to minimize errors and make it, therefore, more qualitative and useful.

Firstly, the different types of errors that may appear when conducting a survey are reviewed; secondly, different techniques and strategies to minimize those errors are listed; finally, an analysis of some questions from the April 2020 CIS barometer is made.

\section{OS DISTINTOS TIPOS DE ERROS NUNHA ENQUISA}

Toda enquisa está destinada a obter información sobre distintos factores en distintos grupos de individuos. A información obtida é utilizada polo demandante da enquisa para diferentes fins. Interesa, xa que logo, que os resultados obtidos sexan o máis fiables dentro do posible pois ditos resultados influirán sobre determinadas tomas de decisión. Para conseguir isto, é importante minimizar os erros de medición da enquisa. 
A preocupación polos controis de calidade nas enquisas xa fora posta de manifesto en 1915 por Gillin. Un ano despois, Hobson inicia o estudo experimental dos efectos no cuestionario do cambio na formulación da pregunta ${ }^{1}$.

Entre 1936 e 1949, Hadley Cantril, fundador de The Office of Public Opinion Research da Universidade de Princeton, deseñou varios experimentos sobre os efectos da redacción das preguntas nos cuestionarios elaborados por Gallup durante eses anos. Este mesmo autor culmina en 1944 a análise dos nesgos debidos ao entrevistador ${ }^{2}$.

Tamén en 1944, Deming enumerou os trece factores que poden afectar á utilidade dunha enquisa. Entre eles está o da Imperfección no deseño do cuestionario que inclúe ${ }^{3}$ :

(a) a ausencia de claridade nas definicións; ambigüidade; variación do significado da mesma palabra para diferentes grupos de xente; provocar unha resposta debida a unha mala interpretación;

(b) a omisión de preguntas que poderían esclarecer a interpretación doutras;

(c) palabras con carga emocional; preguntas dirixidas; limitar as respostas a un patrón;

(d) erro na percepción de que tabulacións serían as máis significativas; e

(e) a redacción de preguntas cunha linguaxe excesivamente técnica ou ampulosa que animan ao entrevistado a non responder.

Trala realización de 900 experimentos split-ballot ${ }^{4}$, Sudman e Bradburn demostraron en 1974 que os efectos da formulación da pregunta afectan tanto ás preguntas de opinión coma ás de feito. Ademais, mostraron que a maioría dos erros de medición débense á forma do cuestionario ${ }^{5}$ : a extensión, a orde das preguntas, o formato aberto ou pechado, o emprego de palabras ambiguas ou de difícil comprensión, a saliencia ${ }^{6}$ da pregunta para o entrevistado, e o emprego de axudas ao recordo.

Schumman e Presser realizaron entre 1971 e 1980 unha investigación na que analizaban os efectos nos resultados da enquisa producidos pola forma da pregunta, a súa redacción e o contexto. 0 traballo foi publicado en 1981 e tivo unha gran repercusión na literatura sobre enquisas. Entre outros resultados, comprobaron que pequenos cambios na formulación das preguntas poden provocar grandes diferenzas nas respostas ${ }^{7}$.

A pesar de todos os estudos mencionados, non é o erro de medición o máis medido nas enquisas, senón o erro mostral recollido na ficha técnica. Nesta recompílase quen fai a enquisa, onde (o ámbito xeográfico), a quen (a poboación a estudo), o tamaño da mostra e o procedemento seguido para a súa selección, e o xa mencionado erro mostral para unhas certas marxes de confianza e

1 [Cea (2005)] p. 78

${ }^{2}$ [Cea (2005)] p. 78

${ }^{3}$ [Deming 2006] p. 36

${ }^{4}$ No método do split-ballot divídese a mostra en dous ou máis grupos, formulándose a mesma pregunta a todos, pero con diferentes formatos de resposta para cada grupo.

${ }^{5}$ [Sudman\&Bradburn 1974], citados por [Cea 2005] p. 78

${ }^{6} \mathrm{~A}$ hipótese da saliencia (en inglés, salience) consiste en que unha resposta concreta faise máis conveniente ou máis atractiva por medio dun proceso crecente de concienciación creado por preguntas precedentes [Schuman e Presser (1981)] p. 44

${ }^{7}$ [Schuman\&Presser 1981], citados por [Cea 2005] p. 78 
heteroxeneidade ${ }^{8}$. Na ficha técnica non só non se recolle información sobre os erros de medición, senón tampouco doutros erros de non observación, como son os erros de non cobertura (a quen da poboación se excluíu da mostra) e os erros de non resposta (a composición da mostra final e a súa correspondencia coa poboación de interese) ${ }^{9}$.

Outros tipos de erros, que non son obxecto de análise deste artigo, son debidos ao entrevistador, ao entrevistado, ao procesamento da información e a súa interpretación etc. Hansen, Hurwitz e Madow clasificaron os distintos tipos de erros en erros sistemáticos (os que non suman cero cando se promedian as observacións mostrais e polo que haberá unha subestimación ou sobreestimación dos valores "reais" na poboación), e erros variables (os que si suman cero cando se promedian) ${ }^{10}$. Estes mesmos autores propuxeron o concepto de erro total da enquisa no que se recollan todos os distintos tipos de erros ${ }^{11}$.

\section{2.- A MELLORA DO CUESTIONARIO}

As melloras no cuestionario deben encamiñarse a evitar os erros de medición que se deban ${ }^{12}$ :

a) Á desigual interpretación dos termos da pregunta polo emprego de palabras ambiguas ou con distintas connotacións.

b) Á redacción da pregunta, á súa introdución e formulación concretas. A obxectividade perséguese como requisito de calidade da pregunta. Como di Payne, "unha boa pregunta é, entre outras cousas, aquela que non afecta á resposta"13.

c) Ás opcións de resposta: que alternativas se ofrecen e en que orde.

d) Á orde e o contexto da pregunta.

e) Ó tema da pregunta: cando esta poida inhibir ao entrevistado de dar unha resposta sincera; ao ocultar a intencionalidade da pregunta; ao proporcionar respostas flexibles ou atenuar a gravidade da pregunta; ao redactar a pregunta nun vocabulario familiar ao entrevistado, nun formato longo (máis ca curto) e aberto; ao aleatorizar as opcións de resposta ou ao cargar deliberadamente a pregunta (asumir a conduta e preguntar pola súa frecuencia ou outros detalles).

Estes e outros erros de medición requiren para a súa detección e redución, a comprobación previa do cuestionario, o que se chama o pretest, pero sempre que se axuste ao deseño da enquisa e ás condicións "reais" nas que finalmente se levará a cabo ${ }^{14}$. De Lamater e McKinney censuran a práctica aplicada con frecuencia de facer o pretest do cuestionario en mostras de conveniencia de estudantes, colegas ou amigos, a non ser que sexan a poboación de estudo ${ }^{15}$. Outros procedementos para comprobar a validez da medición son: os xa nomeados experimentos splitballot, os estudos de contraste dos datos da enquisa cos datos de rexistros administrativos, a observación do axuste entre o deseño da enquisa e a súa realización, a avaliación dos cuestionarios

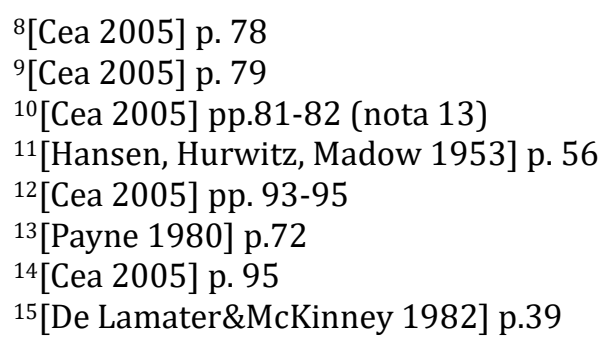


(por expertos), e os estudos de grupo de criterio (pasar o cuestionario a un grupo de persoas das que se sabe, cun certo grao de certeza, que posúen abundancia ou deficiencia do concepto a medir) ${ }^{16}$.

Todos estes métodos axudan a detectar problemas de validez e fiabilidade na enquisa, e do seu resultado emanarán actuacións dirixidas a mellorar a aplicación do cuestionario. Pero calquera modificación terá que ser novamente revisada e avaliada e, quizais, modificada, co cal o proceso pode facer que os custos, en tempo e diñeiro, se incrementen notablemente e os promotores do estudo prescindan deles ${ }^{17}$.

Fáganse ou non algúns dos métodos anteriores, hai outras alternativas para mellorar os cuestionarios que non precisan tanto investimento. Son estas unha serie de estratexias emanadas da experiencia e que se refiren principalmente á estrutura do cuestionario e á elaboración das preguntas. Un bo resumo destes consellos nolo dá o Program on Survey Research (PSR) da Universidade de Harvard. A continuación enuméranse algunhas destas pautas ${ }^{18}$.

\section{Consideracións xerais:}

- Proporcionar instrucións claras ao entrevistado, ben por medio do entrevistador nunha enquisa presencial ou telefónica, ou ben na folla de respostas se é por correo ou múltiple.

- Procurar facer cuestionarios curtos: os entrevistados son máis propensos a responder os cuestionarios curtos ca os longos, e normalmente prestan menos atención aos cuestionarios que parecen longos, monótonos e aburridos.

- Pensar ben a orde das preguntas: as respostas poden estar influenciadas por preguntas previas. É mellor comezar con preguntas de carácter xeral, fáciles de responder para o entrevistado; e deixar as preguntas delicadas e persoais para o final.

- Se se está preguntando unha serie de cuestións similares, ordenalas de maneira aleatoria pode mellorar os resultados.

- Os entrevistados deben responder preguntas que lles sexan aplicables. Nos casos onde algunhas cuestións sexan relevantes só para algúns dos entrevistados, é mellor especificalo.

\section{Tipos de preguntas:}

- $\quad$ Preguntas abertas e preguntas pechadas: nas primeiras o entrevistado responde nos seus propios termos, nas pechadas o entrevistado debe elixir entre un número limitado de respostas que se lle proporcionan.

- As preguntas abertas dan unha gran variedade de respostas, pero consomen máis tempo e requiren máis traballo de análise.

- As preguntas pechadas ben deseñadas, aseguran que todos os entrevistados interpretan as cuestións do mesmo xeito.

\footnotetext{
${ }^{16}$ [Cea 2005] p. 96

${ }^{17}$ [Cea 2005] p. 96

18 [PSR Harvard Univ.]

https://psr.iq.harvard.edu/files/psr/files/PSRQuestionnaireTipSheet_0.pdf
} 
- Os entrevistados son máis proclives a non responder unha pregunta aberta ca unha pechada.

- Preguntas de actitude cunha escala numérica de respostas:

- Xeralmente, proporcionar unha categoría media de número dá mellores resultados. Normalmente, o mellor é escalar entre cinco e sete opcións.

- Os números da escala deben ser etiquetados con palabras claras e sen ambigüidade.

- As preguntas que usan as etiquetas concordo/discordo poden nesgarse cara a resposta "concordo", polo tanto, na medida do posible, é mellor evitar estas etiquetas.

- Para evitar a identificación alto-positivo e baixo-negativo, escribir preguntas nas que as opcións positivas e negativas estean escaladas indistintamente "alto" e "baixo".

- A orde na que as opcións de resposta son presentadas pode influír na elección. Unha boa opción é elixir a orde das opcións de maneira aleatoria, ou rotándoas para evitar tanto o efecto primario (o entrevistado tende a elixir unha das primeiras opcións que se lle presentan) nas enquisas por Internet ou en papel, coma o efecto recente (o entrevistado tende a elixir unha das opcións que escoitou máis recentemente) nas enquisas nas que as opcións son lidas polo entrevistador.

\section{Regras xerais para redactar as preguntas:}

A pregunta ideal cumpre tres obxectivos:

- Mide o concepto subxacente que se pretende obter.

- $\quad$ Non mide outros conceptos.

- Ten o mesmo significado para todos os entrevistados.

Para acadar estes obxectivos, son de utilidade as seguintes regras:

1. Evitar termos técnicos e xerga. As palabras usadas deben ser facilmente comprensibles para calquera que participe na enquisa.

2. Evitar termos vagos ou imprecisos. Normalmente, o mellor é usar termos que teñan o mesmo significado específico para todos os entrevistados.

3. Definir os conceptos de maneira moi específica.

4. Evitar frases complexas. As frases con moitas cláusulas ou construcións inusuais confunden con frecuencia ao entrevistado. Preguntas escaladas que obrigan aos entrevistados a facer cálculos complicados poden causar problemas.

5. Proporcionar marcos referenciais. Asegurarse de que todos os entrevistados están respondendo cuestións acerca do mesmo tempo e lugar.

6. Asegurarse de que as escalas son ordinais. Nunha pregunta escalada, cada punto debe ser claramente máis alto ou máis baixo que o precedente para todos os entrevistados.

7. Evitar preguntas compostas, que teñen varias opcións dentro doutras opcións ${ }^{19}$. Cada pregunta debe medir unha única cousa. Este tipo de preguntas tratan de medir dous (ou

${ }^{19}$ En inglés, double-barrelled questions. 
máis!) conceptos, o cal pode provocar que o entrevistado teña que elixir unha opción coa que concorda parcialmente.

8. As posibles respostas deben cubrir de maneira excluínte todo o abano de posibilidades. Se un entrevistado ten máis dunha resposta para unha pregunta, é mellor permitirlle elixir varias respostas. Se as categorías proporcionadas non anticipan todas as posibilidades, é unha boa idea engadir unha categoría "outros-especificar".

9. Se se quere unha resposta sinxela, hai que asegurarse de que as opcións de resposta sexan únicas e inclúan todas posibles respostas. Se se está medindo algo que non é continuo, redactar as categorías coma un rango.

10. Evitar o uso de linguaxe de mando, emocional ou evocadora.

\section{3.- A ENQUISA DO CIS DE ABRIL DE 2020}

Se ben no barómetro do Centro de Investigacións Sociolóxicas (CIS) do mes de marzo de $2020^{20}$ había sete preguntas relacionadas coa Covid-19, é o barómetro de abril ${ }^{21}$ o primeiro que se realiza en pleno confinamento. Analízanse a continuación algunhas das preguntas de dita enquisa que foron amplamente debatidas nos medios de comunicación e redes sociais. Escríbese a pregunta en castelán, tal e como figuraba no cuestionario, e faise un comentario sobre ela facendo referencia ás regras indicadas no PSR da Universidade de Harvard.

P.2 ¿Cree Ud. que la información que está dando el Gobierno y los/as responsables del tema sobre el COVID-19 es suficiente o le gustaría a Ud. tener más información?

COMENTARIO: Non cumpre a regra 8, non cubre todo o abano de posibilidades: pode haber entrevistados que consideren que a información é excesiva.

P.4 ¿Cree Ud. que deberían tomarse medidas más estrictas para evitar que se salga a la calle, o cree que es suficiente con lo que se está haciendo?

COMENTARIO: 0 mesmo que na pregunta 2, alguén pode considerar que as medidas son excesivas.

P.5 Más en concreto, ¿estaría Ud. de acuerdo con que en España no se permitiese salir a la calle y que las medicinas y suministros alimentarios se llevaran a las casas por personal especializado, como se ha hecho en China?

COMENTARIO: Como indica o PSR, os entrevistados deben responder preguntas que lles sexan aplicables. Un entrevistado que considera excesivas ou que está de acordo coas medidas tomadas suponse que está en contra de máis restricións. Esta pregunta só debería ir dirixida aos que consideran que se deberían tomar máis medidas (regra 5). 0 correcto sería engadir ao comezo da pregunta o parágrafo: Só para aqueles que na pregunta 4 contestaron que cren que se deberían tomar medidas máis estritas.

P.6 ¿Cree Ud. que en estos momentos habría que prohibir la difusión de bulos e informaciones engañosas y poco fundamentadas por las redes y los medios de

${ }^{20}$ Dispoñible en: http://www.cis.es/cis/export/sites/default/Archivos/Marginales/3260_3279/3277/cues3277.pdf

21 Dispoñible en: http://www.cis.es/cis/export/sites/default/-

Archivos/Marginales/3260_3279/3279/cues3279.pdf 
comunicación social, remitiendo toda la información sobre la pandemia a fuentes oficiales, o cree que hay que mantener libertad total para la difusión de noticias e informaciones?

COMENTARIO: 0 enunciado da pregunta é excesivamente longo e faille perder á pregunta claridade e concisión (regra 4); e expón unha pregunta composta (a evitar segundo a regra 7) na que se introducen varias ideas en dúas opcións que non teñen por que coincidir coa opinión do entrevistado. As ideas que introduce a pregunta son:

A: prohibir a difusión de rumores e informacións enganosas e pouco fundamentadas polas redes e os medios de comunicación social.

B: remitir toda a información a fontes oficiais.

C: manter liberdade total para a difusión de noticias e informacións.

Ao introducir as dúas primeiras ideas na mesma opción, estase nesgando a resposta. Un entrevistado que considere que hai que prohibir a difusión de informacións falsas pero que está a favor de manter liberdade total para a difusión de noticias e informacións (a idea $\mathrm{C}$ non menciona as informacións falsas) ten un dilema para escoller a resposta, obrigándolle a elixir entre unha opción coa que concorda parcialmente, e outra opción coa que está de acordo.

Algúns autores chaman a este tipo de cuestións, preguntas trampa, que conducen ao entrevistado a expresar o que quere o autor da enquisa ${ }^{22}$.

O correcto sería substituír esta pregunta por outras dúas (utilizando as propias frases da pregunta):

6a.- ¿Cree Ud. que en estos momentos habría que prohibir la difusión de bulos e informaciones engañosas y poco fundamentadas por las redes y los medios de comunicación social? Con respostas claras: Si, Non, Non sabe ou Non contesta.

6b.- ¿Cuál es su opinión sobre el tratamiento de la información?

(a) Cree que se debe remitir toda la información sobre la pandemia a fuentes oficiales.

(b) Cree que hay que mantener libertad total para la difusión de noticias e informaciones

Tamén con respostas claras e excluíntes (a) ou (b).

P.14 En circunstancias como las actuales, ¿cree Ud. que los partidos y líderes de la oposición tienen que colaborar y apoyar al Gobierno en todo lo posible, dejando sus críticas o discrepancias para otros momentos, o que deben continuar criticando y oponiéndose al actual Gobierno en todo lo que consideren?

COMENTARIO: Ademais dun enunciado excesivamente longo, trátase doutra pregunta trampa. Vólvense a mesturar varias ideas non excluíntes. Unha persoa pode pensar que hai que apoiar ao Goberno en todo o posible e, ao mesmo tempo expresar críticas coa súa actuación. As catro ideas que aquí entran en xogo son:

${ }^{22} \mathrm{Na}$ páxina web de e-nquest (www.e-nquest.com), un sistema web para a xestión integral de cuestionarios deseñado pola spin-off ESAM da Universidade de Valencia, danse consellos para facer boas preguntas en cuestionarios (https://www.e-nquest.com/consejos-definirpreguntas-encuesta/). Di: En ningún caso se debe tratar de preguntas "trampa" que puedan conducir al encuestado a expresar lo que el cliente quiere. 
A: los partidos y líderes de la oposición tienen que colaborar y apoyar al Gobierno en todo lo posible.

B: dejar sus críticas o discrepancias para otros momentos.

C: continuar criticando.

D: oponerse al actual Gobierno en todo lo que consideren.

Esta pregunta poderíase desdobrar noutras dúas (utilizando as propias frases da pregunta) que si abarcarían todas as posibilidades dunha forma clara:

14a.- En circunstancias como las actuales, ¿cree Ud. que los partidos y líderes de la oposición tienen que colaborar y apoyar al Gobierno en todo lo posible, o que deben oponerse al actual Gobierno en todo lo que consideren?

14b.- En circunstancias como las actuales, ¿cree Ud. que los partidos y líderes de la oposición tienen que dejar sus críticas o discrepancias para otros momentos, o que deben continuar criticando en todo lo que consideren?

P.16 ¿Cree Ud. que cuando termine la crisis del COVID-19 debería hacerse un esfuerzo especial para intentar llegar a grandes acuerdos ante la crisis económica y laboral, o cree que lo mejor es que cada partido plantee sus propias alternativas y puntos de vista?

COMENTARIO: 0 enunciado é confuso (regra 4). 0 feito de que cada partido formule as súas propias alternativas e puntos de vista non exclúe que non estea disposto a discutilas e chegar a acordos que impliquen a renuncia a algunhas das súas propostas. Novamente dase a elixir entre dúas opcións coas que un entrevistado podería estar de acordo (regra 7).

Ademais, hai posibilidades que non se contemplan (regra 8). Pódese chegar a acordos puntuais nalgúns aspectos sen necesidade de optar polo todo ou nada como suxire a pregunta. Unha formulación máis clara, por exemplo, sería:

¿Cree Ud. que cuando termine la crisis del COVID-19 y ante la crisis económica y laboral...

- ... debería hacerse un esfuerzo especial para intentar llegar a grandes acuerdos?

- ... debería hacerse un esfuerzo especial para intentar llegar a acuerdos puntuales en aspectos clave, especialmente en los campos de la economía y el mundo laboral?

- ... cada partido debería plantear sus propias alternativas y puntos de vista, negándose a aceptar otras posibilidades?

P.17 Refiriéndonos a la situación económica general de España al margen del COVID-19, ¿cómo la calificaría Ud.: muy buena, buena, mala o muy mala?

COMENTARIO: Pregúntase por unha situación ficticia, non existe un marco referencial (regra 5). A situación económica non se pode separar de ningún condicionante. Máis correcto sería preguntar pola situación económica ata que apareceu a Covid-19, por exemplo:

Refiriéndonos a la situación económica general de España previa a la aparición del COVID-19, ¿cómo la calificaría Ud.: muy buena, buena, mala o muy mala?

Ou, se se quere saber a opinión que ten o entrevistado da situación económica no momento da enquisa, deberíase preguntar simplemente: 
¿Cómo calificaría Ud. la situación económica actual de España?: muy buena, buena, mala o muy mala

\section{BIBLIOGRAFÍA:}

- D'Ancona, M. A. (2005). CIS (Centro de Investigaciones Sociológicas), ed. La senda tortuosa de la "calidad" de la encuesta. REIS (Revista Española de Investigaciones Sociológicas) (en castelán) (Madrid) (111): 75-103. ISSN 0210-5233. Dispoñible en http://www.reis.cis.es/REIS/PDF/REIS_111_051168262751380.pdf

- $\quad$ De Lamater, J.; McKinney, K. (1982). Response-effects of question content. En Dijkstra, W.; Van der Zouwen, J. Response Behaviour in the Survey-interview (en inglés). Nova York: Academic Press. pp. 13-48. ISBN 0122162609.

- Deming, W. E. (1944). American Sociological Association, ed. On Errors in Surveys. American Sociological Review (en inglés) (SAGE Publications) 9 (4): 359-369. Dispoñible unha vista previa en https://www.jstor.org/stable/2085979

Un extracto do artigo anterior pódese ler en:

- Deming, W. E. (2006). The American Statistical Association, ed. On Errors in Surveys (An Excerpt). The American Statistician (en inglés) (Taylor\&Francis, Ltd) 60 (1): 34-38. Dispoñible en https://www.jstor.org/stable/27643725

- Hansen, M. H.; Hurwitz, W. N.; Madow, W. G. (1953). Sample Survey Methods and Theory. Wiley Classics Library (en inglés). 1: Methods and Applications. Wiley. ISBN 0471006289.

- $\quad$ Harrison, C. H. (actualizado 2007). Harvard University, ed. Tip Sheet on Question Wording de Program on Survey Research (PSR) (en inglés). Dispoñible en https://psr.iq.harvard.edu/files/psr/files/PSRQuestionnaireTipSheet_0.pdf

- Payne, S. L. (1951). The Art of Asking Questions. Studies in Public Opinion (en inglés). Princeton University Press. ISBN 0-691-093040. Dispoñible vista previa en https://www.casadellibro.com/ebook-the-art-of-asking-questionsebook/9781400858064/3054458

- Schuman, H.; Presser, S. (1996) [1 ${ }^{a}$ ed. 1981]. Questions and answers in attitude surveys. Experiments on question form, wording and context (en inglés). SAGE Publications. ISBN 07619-0359-3.

- $\quad$ Sudman, S.; Bradburn, N. M. (1974). National Opinion Research Center, ed. Response Effects in Surveys; a Review and Synthesis. Monographs in Social Research (en inglés) 16. Chicago: Aldine Publishing Company. ISBN 0-202-30270-9. 